\title{
The Role of Leisure Industry in Municipal Economic Growth
}

\author{
Madelon C. Briz
}

\begin{abstract}
This research deals with the role of the leisure industry and the implemented measures on safety and security towards the economic growth of the municipalities in the third district of Laguna Province in the Philippines. This study comprised 100 randomly selected samples from the seven municipalities. The statistical tools used were mean, standard deviation and t-test. The results of the study showed that the leisure industry as well as the implemented measures on safety and security contribute to the overall development of the municipalities which were measured in terms of employment, service and income. I was clear that the leisure industry generates more income than other industries which essentially helped improved funds of the municipalities. As the current study generated data from survey, the results are mere perceptions of the key stakeholders. Further studies are encouraged on the measurement of the actual income contribution of the industry to the municipalities.
\end{abstract}

Keywords: leisure industry, revenue, services, quality, income

Suggested Citation: Briz, M.C. (2021). The Role of Leisure Industry in Municipal Economic Growth. International Journal of Academe and Industry Research, Volume 2 Issue 4, pp. 16 - 31.

\footnotetext{
About the author:

Instructor 1, Laguna State Polytechnic University- San Pablo City Campus
} 


\section{Introduction}

In a personal perspective, leisure gives a chance to develop skills, friendship and selfconfidence. It helps enjoy new experiences, adventures and challenges. With staying healthy, leisure activities are freely chosen and can be done in places that are good and comfortable. For many people, participation in leisure improves physical and mental health. It also refers to time spent away from work and all manner of business as relaxation time. Research shows that increased physical activities can lead to fewer health problems and higher productivity at work, especially when combined with a balanced diet and a healthy life style. Leisure is important because everyone needs a little bit of relaxation in their life. Having leisure helps a person relieve stress, have time for themselves and just to recharge their body and mind. Leisure is very important for one's mental health. Leisure is important because life should not be all work, no play. It is important for the mind and body to get the revival it needs after a long week's hard work.

An industry that provides goods or services for activities that people do for entertainment and enjoyment is what is called the leisure industry (Novak, 2017). The leisure industry is one of the largest, most diverse, profitable and constant, and fastest-growing industry. It is the segment of business focused on entertainment, recreation, and tourism related products and services. It is constantly changing because of new innovations and economic trends. There are many reasons why there are so many changes in the leisure industry because the leisure industry in itself is an open market in which many people can and have developed. These fields include restaurants, amusement parks, theaters, hotels, gaming places, venues for musical groups or lectures, and sporting arenas. These also include spas, gyms, and areas where one can conduct sports, like golfing or boating as part of the leisure industry. Anything that is made to be enjoyed, and is made to occupy one's leisure hours is essentially part of the leisure industry.

In the Philippines, the 2019 Philippine Statistics Authority data showed that the leisure travel and tourism spending in the country was $8 \%$, an increase from $3.7 \%$ in 2000 with an average annual rate of 4.67\%. The 2018 Census of Philippine Business and Industry: Arts, Entertainment, and Recreation (Section R) includes "five industry groups covering the activities to meet varied cultural, entertainment and recreational interests of the general 
public, including live performances, operation of museums sites, sports, gambling and recreation activities. Establishments engaged in creative, arts and entertainment activities; libraries, archives, museums, and other cultural activities; gambling and betting activities; sports activities; and other amusement and recreation activities." In 2018 a total of 4,087 establishments were engaged in arts, entertainment and recreation activities, an increase of 34.2 percent from the 3,046 establishments reported in 2012. Among these, 2,037 establishments or 49.8 percent of the total count were engaged in other amusement and recreation activities. Establishments engaged in gambling and betting activities with 1,384 establishments (33.9\%) ranked second, followed by establishments engaged in sports activities with 558 establishments (13.7\%). Across regions, CALABARZON recorded the highest number of establishments engaged in arts, entertainment, and recreation activities with 505 establishments (12.4\%). Establishments in arts, entertainment, and recreation industry employed a total of 75,968 employees, a growth of 22.9 percent from 61,815 employees in 2012. An average of 19 employees per establishment was computed at the national level.

The economic impact of leisure industry has been commonly viewed as a positive force which increases total income for the local economy, foreign exchange earnings for the host country, direct and indirect employment, and tax revenues. It also stimulates secondary economic growth. As the years passed, tourism has experienced continued growth and deepening diversification to become one of the fastest growing sectors in the world. Leisure industry has become a big business and has been considered as a fastest growing industry. It opens up a new window for resources, both investments and generation leading to employment as well as socio-economic development of the local communities. It also plays an important part to the economy of the country. The growth of the economy had seen a major change because of its leisure industry growth. Leisure industry has established itself as an important source of economic development in different regions in the world. As a result, leisure and tourist spots help to contribute for generating revenue and also for job creation for the community.

According to the data by the United Nations World Tourism Organization (UNWTO), the total international tourism received in the world in 2018 was 1,643.2 billion dollars in visitor exports (Mandeep \& Nitasha, 2012). This is expected to increase to 2.196 billion by 
2029 at an increase of $3.8 \%$ (World Travel \& Tourism Council Report, 2019). In the Philippines, the total revenue generated by establishments engaged in arts, entertainment and recreation in the Philippines reached $\mathrm{PhP} 230.7$ billion in 2018 while expenses incurred totaled to $\mathrm{PhP} 181.8$ billion. This is a 75.2 percent increase in total revenue, and 65.0 percent increase in total expenses from their corresponding values in 2012. The increasing trend in the revenues provides indication that the industry is contributing much to the economic development of the country.

According to Chung-ki Min, et al. (2016), the leisure tourism contributes to economic growth at an early stage of economic development, but its contribution becomes weaker as the economy develops. In this context, this study determines the contribution of the leisure industry and its implemented measures on safety and security toward the economic growth of municipalities. Specifically, this study aimed to determine the extent of contribution of leisure industry to the overall development of municipalities, assess the status of implemented measures on safety and security of the leisure industry and describe the level of economic growth of municipalities on employment, service and income. Further, this study aimed to find-out whether the contribution and the implemented measures on safety and security significantly influence the way leisure industry targeted to bring-out economic growth of municipalities in third district of Laguna.

\section{Literature review}

\subsection{The leisure industry}

According to Leitner and Leitner (2011), pure leisure refers to those activities freely engaged in that are totally intrinsically motivated. The activity is engaged for its own sake, with extrinsic rewards not considered. Edginton and Chen (2014) further stated that leisure provides opportunities to enhance and enlarge choices and freedom in the daily decision one makes. Leisure is valued for many reasons, not the least of which is the opportunity to engage in freely chosen life experience.

The leisure industry provides products and services for activities that people do for entertainment and enjoyment. The leisure industry encompasses entertainment, recreation and tourism related goods and services. Areas of the leisure sector include sports, gambling 
and health and fitness. This is also claimed by Anser, et al. (2021) that the scope of leisure industry for the purposes of these criteria includes, sport, play, shopping formal and informal use of leisure time. According to Mikalauskas and Kaspariene (2016), leisure is a fundamental component of life which involves freedom and provides opportunities to choose and make decision for the proper well-being. As such, it covers wide ranges of areas such as sport, recreation, health and fitness, playwork and gaming. The leisure experience enhances human condition (Bopp \& Kaczynski, 2010). It is also connected to a range of economic activities such as cultural industries (Hesmondhalgh 2007) or the creative economy (Howkins, 2001). These may even include cultural tourism and heritage, museums and libraries and animal shows (Banhidi \& Flack, 2013). Another important segment of the industry is the leisure sport which refers to "products and services concerning sport activities and the total operational activities related to these products and services." (Minwei, 2015).

Figure 1

Number of establishments in the arts and recreation industry in the Philippines in 2017, by region

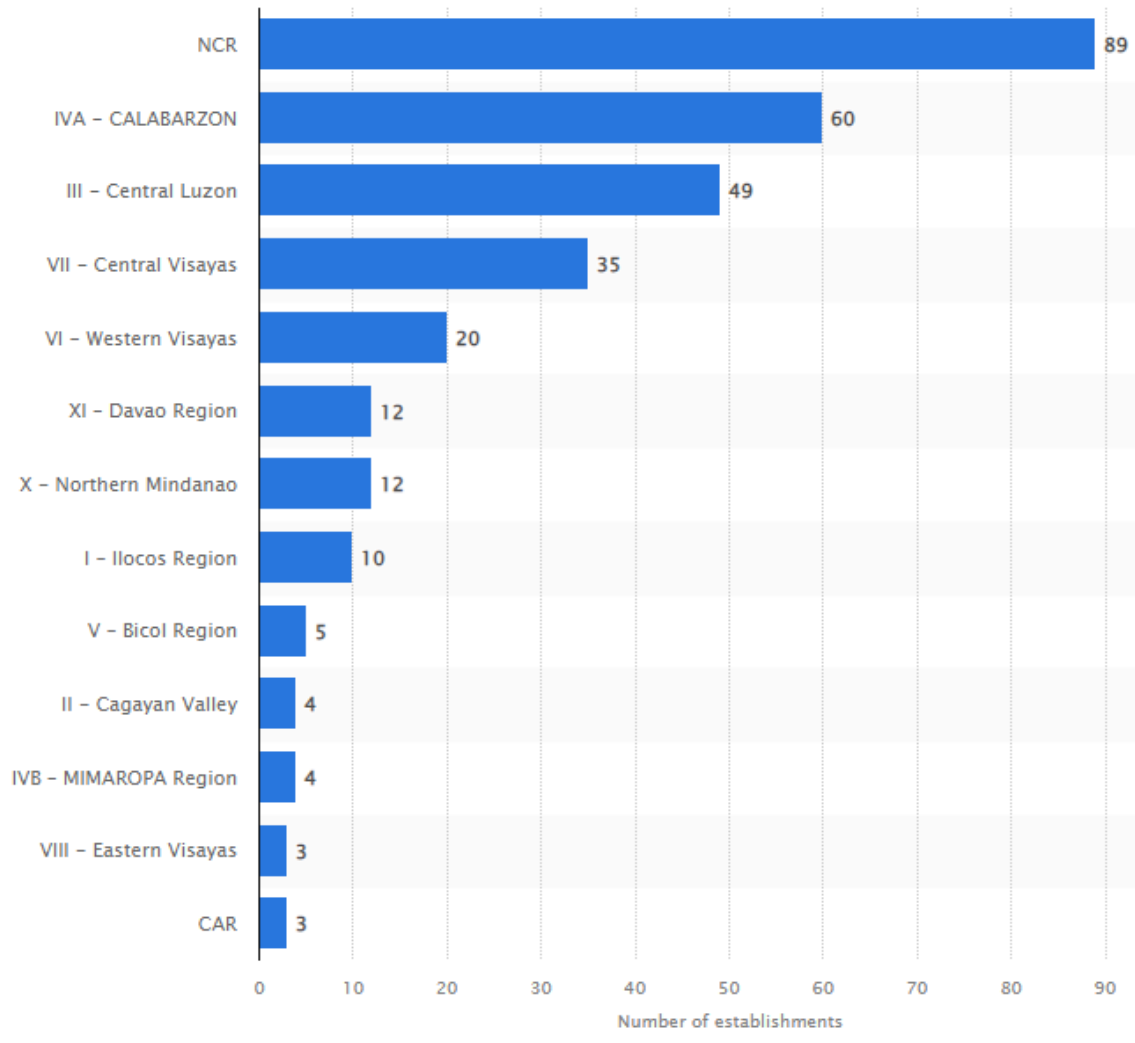

Source: Statistica.com 
Figure 1 shows the 2017 statistics on the number of establishments in the arts and recreation industry in the Philippines. The highest number by region is 89 situated in the NCR followed by 60 in the CALABARZON region. The locale of the current study is the latter which justifies the need for the assessment on the contribution of the industry on the economic growth of the municipalities in the region.

\subsection{Growth of leisure industry}

Tourists flock to leisure destinations thereby, improving the economic growth of the location. But for tourists to continually patronize a leisure destination, satisfaction with the products and services offered is a must. Sherman (2018) states that the choice of business location affects the business income and expenses. Even in an age where people can buy and sell through the internet and project teams can collaborate from various states and countries, location still plays a significant role in the company's success or failure. When the location of business is near the city proper, it has the possibility to earn more than those businesses which are far from the city. According to Norjanah et al. (2014), most tourist spots grow rapidly when those destination places are near major populated and more technologically advanced areas. It simplifies the attractions of tourist spots to the people who want the area where tourism evolves. It really means that the tourists who want to take holidays are more attracted to travel conveniently when the destinations preferred are short distances. It also shows most tourist spots grow rapidly when those destination places are near major populated and technologically advanced areas. Hence, it will increase the growth and development of tourism and have a better revenue generation.

On the other hand, Agbor (2011) explained that the aim of providing quality services is to satisfy customers because quality is one of the things that consumers look for in an offer and quality can also be defined as the totality of features and characteristics of a product or services that bear on its ability to satisfy stated or implied needs that is why it is evident that quality is also related to the value of an offer, which could evoke satisfaction or dissatisfaction on the part of the consumer. Measuring service quality is a better way to dictate whether the services are good or bad and whether the customers will or are satisfied with it. Similarly, Mill (2007) cites that service pleases the customer, which adds to the customer's enjoyment. It increasingly becomes method of differentiation; managers will have 
to become adept to getting feedback from customers of providing service to an increasingly diverse customer base. Azmat and Clemes (2021) add that the guest wants common courtesy, which means recognition, respect and a friendly welcome. A principal reason people dine out is the desire for sociability. Bak (2019) explained that the revenue can come from potential new customers as well as from existing customers. Since it costs fine as much as to attract new customers to maintain existing ones, it is more cost effective for the company to focus on increasing the loyalty of their existing customers. The most revenue area and cost savings can be attained in servicing the same customers repeatedly as compared to servicing new individual's accounts.

These literatures are classification of good service through tourist interaction in the leisure industry in Laguna District III. Revenue can then be gotten from patronage of the tourists, most especially if they are satisfied with the products and services offered.

\subsection{Leisure industry and Economic Growth}

As every nation moves toward an economy that is globalized and is networked by computers, the provision of leisure and tourism services change in numerous ways, customizing services based on increasing levels of information about customers. The characteristics of a networked economy, as described by Kelly (1998), include numerous implications for the delivery of leisure and tourism services. According to Romer (1990), investment in human capital, innovation and knowledge are significant contributors to economic growth.

Bascom (2016) believes that economic growth will be better suited to meet the wants of individuals and resolve socio-economic problems such as poverty; thereby ensuring the well-being of the economy and improving standard of living, by raising incomes providing jobs. In addition, economic growth can possibly even protect the environment by the creation of parks, reserves, and implementation of key policies. Consequently, some economists have argued that economic growth will eventually lead to an improvement in the environment and also to an improvement in the environment and also to the welfare of an individual.

One of the basic measures of growth in business is its income. It is also one of contributory factors in economic growth and development. Income is the earnings of the business from the sales of goods or service rendered (Ballada, 2014). As suggested by 
Mankiw (2007), when judging whether the economy is doing well or poorly, it is natural to look at the income that everyone in the economy is earning. As stated by Ukabuilu et al. (2015), the common terms for the added value created in transforming resources into more desirable states includes profit, income or earnings. Accountants measure the added value as the difference between cost of a product or service and the selling price of that product or service.

There are several studies linking leisure and tourism to economic growth. For example, Kim et al. (2006) conducted a study in Taiwan which tested the relationship between tourism sector and economic growth for Taiwan. The results showed a bidirectional causal relationship between tourism and economic growth. This is similar to the findings of Lee and Chang (2008) that there is a unidirectional relationship between tourism and growth for OECD countries. In Pakistan, Khalil and Kakar (2007), determined the effects of the short and long-term causality between economic expansion and tourism receipts which showed a long-term association between the development of tourism sector and the economic growth. This long-term associated was also proven by Salleh et al. (2011) on the relationship between tourism sector, trade and growth in ASEAN countries which showed a long-term correlation among foreign tourist arrival, economic growth and trade. In Jordan, tourism has an important role in its economic growth as tested by Orieqat and Saymeh (2015). This role was seen with job creation, earnings, infrastructure and increase in GDP in India. In the study of Dayananda and Leelavathi (2016), there was sustained and inclusive economic growth due to extension of tourism sector. However, Ozturk and Acaravci (2009) showed no unique long-term or equilibrium relationship between the real GDP and international tourism for Turkey.

\section{Methodology}

The descriptive method of research was used in this study in order to assess the contribution of leisure industries and implemented measures on safety and security toward economic growth of municipalities in the third district of Laguna Province in the Philippines. 
It is the design that gathers information about the problem, collates the data to test a hypothesis and answer the questions concerning to the status of the subject of the study.

The study employed self-administered questionnaire, a set of orderly arranged questions, carefully prepared to generate answers to the specific problem of the study. The questionnaire contains four parts: Part I determined the extent of contribution of leisure industry to the overall development of Municipalities; Part II assessed the status of the implemented measures on safety and security of the leisure industry in the municipalities; Part III identified the level of economic growth in municipalities with regard to employment, service and income; and Part IV calculated the significant relationship of the contribution and implemented measures on safety and security to the economic growth of municipalities.

The respondents of the study include 100 key stakeholders of leisure industry businesses such as tourist spot visitors, recreation facilities, restaurants, hotel and spa distributed as per municipality as follows: 20 from Alaminos; 40 from San Pablo City; 5 from Rizal; 5 from Victoria; 10 from Calauan; and 20 from Liliw.

The statistical tools used were average mean, standard deviation and t-test. Weighted mean and standard deviation was used to determine the extent of contribution of leisure industry to the overall development of municipalities, the status of implemented measures on safety and security of the leisure industry in the municipalities, and the level of economic growth in municipalities with regard to employment, service and income. The t-test was used to determine the significant relationship of the contribution and implemented measures on safety and security to the economic growth of municipalities.

\section{Findings and Discussion}

The major findings of the study are arranged according to the specific research objectives: (1) the extent of contribution of leisure industry to the overall development of municipalities; (2) the status of implemented measures on safety and security of the leisure industry in the municipalities; (3) the level of economic growth in municipalities with regard to employment, service and income; and (4) the significant relationship of the contribution and implemented measures on safety and security to the economic growth of municipalities. 


\section{Table 1}

Extent of Contribution of Leisure Industry to the Overall Development of Municipalities

\begin{tabular}{lcccc}
\hline Indicators & Mean & SD & Interpretation \\
\hline $\begin{array}{l}\text { 1. Leisure industries contribute in the protection of the } \\
\text { environment. }\end{array}$ & 4.18 & 0.66 & Agree \\
$\begin{array}{l}\text { 2. Encourage tourism and promotes awareness of } \\
\text { culture and history. }\end{array}$ & 4.25 & 0.57 & Agree \\
$\begin{array}{l}\text { 3. Leisure industry helps communities to increase job } \\
\text { opportunities. }\end{array}$ & 4.15 & 0.60 & Agree \\
$\begin{array}{l}\text { 4. Provides a wide range of leisure activities for } \\
\text { customers in a safe, secure and responsible } \\
\text { environment } 4.20\end{array}$ & 0.59 & Agree \\
$\begin{array}{l}\text { 5. Attracts a large proportion of part- time and flexible } \\
\text { workers }\end{array}$ & 4.22 & 0.61 & Agree \\
\hline Overall & 4.20 & 0.61 & Agree \\
\hline
\end{tabular}

Legend: 4.50-5.00 Strongly Agree; 3.50-4.49 Agree; 2.50-3.49 Moderately Agree; 1.50-2.49 Disagree; 1.00-1.49 Strongly Disagree

It can be gleaned from Table 1 that the leisure industry has a great extent of contribution to the overall development of the selected municipalities in the $3^{\text {rd }}$ district of Laguna. The level of the respondents' agreement on the indicators was manifested by an overall mean of 4.20. The highest of the indicators is the encouragement of tourism and the promotion of culture and history awareness. This is followed by the targeting of part-time and flexible workers which were given either self-employment as entrepreneur or permanent employment opportunity. However, the lowest mean was given to the ability of the leisure industry to protect the environment.

It can be observed that there are several actions taken by the tourism office to ensure that they encourage tourism and promote awareness of culture and history. There are festivities conducted in each municipality that ensure to protect the identity and local beliefs of the people to capture known and historic principles. When tourists were the target audience in festivities that they are attracted and eager to know the history based from the local tradition of a certain municipality the more potential linkage and growth identities can be observed (Aguda et al, 2013).

Other indicators that make the leisure industry to contribute to a great extent in the overall development of the municipality are the programs that attract a large proportion of part-time and flexible workers. Similar to Bascom (2016), the economic growth of the 
municipalities in the locale support the wants of individuals and resolve socio-economic problems such as poverty as it provides employment and self-employment.

\section{Table 2}

Status of Implemented Measures on Safety and Security of the Leisure Industry

\begin{tabular}{lccc}
\hline Indicators & Mean & SD & Interpretation \\
\hline $\begin{array}{l}\text { 1. Advised customers of safety procedures in high-risk } \\
\text { areas to ensure minimal disruption. }\end{array}$ & 4.24 & 0.60 & Agree \\
$\begin{array}{l}\text { 2. Employees follow safety precautions for the tourist. } \\
\text { 3. The safety and security procedure are well }\end{array}$ & 4.29 & 0.60 & Agree \\
implemented by the management. & 4.18 & 0.63 & Agree \\
$\begin{array}{l}\text { 4. Employees follow standard sanitation process to } \\
\text { maintain cleanliness. }\end{array}$ & 4.26 & 0.60 & Agree \\
5. Management is responsive to customers' needs. & 4.26 & 0.68 & Agree \\
\hline Overall & 4.25 & 0.62 & Agree \\
\hline $\begin{array}{l}\text { Legend: 4.50-5.00 Strongly Agree; 3.50-4.49 Agree; 2.50-3.49 Moderately Agree; 1.50-2.49 Disagree; 1.00-1.49 Strongly } \\
\text { Disagree }\end{array}$
\end{tabular}

In table 2, the status of the implemented measures on safety and security of the leisure industry in the municipalities is summarized. It indicates that "advised customers of safety procedures in high risk areas to ensure minimal disruption" acquired a mean score of 4.24 and standard deviation of 0.60 and has remarks of "agree." The indicator "employees follow safety precautions for the tourist" acquired a mean score of 4.29, standard deviation of 0.60 , equivalent to 'agree'. The next indicator, "the safety and security procedure is well implemented by the management" got 4.18 with standard deviation of 0.63 interpreted as agree. "Employees follow standard sanitation process to maintain cleanliness" obtained a mean score of 4.26, standard deviation of 0.60 , and remarks of 'agree.' Lastly, the indicator "Management is responsive to customers' needs" acquired a mean score of 4.26 with an standard deviation of 0.68 , interpreted as agree.

The results clearly indicated that the leisure industry ensure the safety and security of the tourists and other visitors. The municipalities assessed in the study provide measures for the sustainability of the businesses within the area. These measures are necessary for the continuous development of the industry. As suggested by Bointon et al. (2016), the safety and security procedures need to be identified. 


\section{Table 3}

Level of Economic Growth in Municipalities in terms of Employment, Service and Income

\begin{tabular}{|c|c|c|c|}
\hline Indicators & Mean & SD & Interpretation \\
\hline \multicolumn{4}{|l|}{ Employment } \\
\hline $\begin{array}{l}\text { 1. Employee receives substantial salary from the } \\
\text { income generated from the leisure industry }\end{array}$ & 3.91 & .67 & High \\
\hline 2. Management can still hire additional employees. & 3.99 & .59 & High \\
\hline $\begin{array}{l}\text { 3. Contractual or part time employees are hired } \\
\text { during peak seasons. }\end{array}$ & 4.05 & .66 & High \\
\hline \multicolumn{4}{|l|}{ Service } \\
\hline $\begin{array}{l}\text { 1. A large portion of income of the leisure industries } \\
\text { comes from services. }\end{array}$ & 4.09 & .65 & High \\
\hline $\begin{array}{l}\text { 2. Leisure industries are involved in government } \\
\text { projects. }\end{array}$ & 3.53 & .72 & High \\
\hline \multicolumn{4}{|l|}{ Income } \\
\hline $\begin{array}{l}\text { 1. Leisure industry generates more income than other } \\
\text { industries }\end{array}$ & 4.01 & .71 & High \\
\hline $\begin{array}{l}\text { 2. The municipality recognizes the leisure industry as } \\
\text { a major source of income }\end{array}$ & 3.49 & .71 & Average \\
\hline Overall & 3.84 & .68 & High \\
\hline
\end{tabular}

Table 3 shows the level of economic growth in municipalities with regards to employment, service, and income. It indicates that leisure industry generates more income from services $(\bar{X}=4.09 ; \sigma=0.65)$ and even higher than other industries $(\bar{X}=4.01 ; \sigma=$ $0.71)$, and provide employment to both contractual and part-time ( $\bar{X}=4.05 ; \sigma=0.66)$ and can still hire additional employees $(X=3.99 ; \sigma=0.59)$ with substantial salary $(\bar{X}=3.91 ; \sigma=$ 0.67). The leisure industry also involves government projects ( $\bar{X}=3.53 ; \sigma=0.72$ ) which the municipalities recognize as major source of income $(X=3.49 ; \sigma=0.71)$.

These findings are similar to Plog (2004) on the development of the destination places. As the findings clearly identified the big development of the leisure industry in the province of Laguna, it also contributed much to the revenue of the different municipalities. In addition, the growth of the industry helped developed the community and its people by providing entrepreneurship and employment. Relative to this is the observation of Bak (2019) that the revenue can come from potential new customers as well as from existing customers. By expanding the market, the industry can also improve its income. 


\section{Table 4}

Relationship between Contribution and the Implemented Measures on Safety and Security

\begin{tabular}{ccc}
\hline Variable & Sig. & Interpretation \\
\hline Contribution of Leisure Industry & $.416^{*}$ & Moderate Relationship \\
Implemented Measures on Safety and Security & $.421^{*}$ & Moderate Relationship \\
\hline *Significant **Not Significant & &
\end{tabular}

As illustrated in table 4, the results confirm the significant moderate relationship of the contribution of leisure industry to the economic growth of municipalities with 0.416 and the implemented measures on safety and security to the economic growth of the municipalities with 0.421 .

The results confirm the findings of Anser et al. (2021) on the growth effects of leisure industry to the level of economic development, Kim et al. (2006) on the bidirectional causal relationship between tourism and economic growth, Lee and Chang (2008) on the unidirectional relationship between tourism and growth, Salleh et al. (2011) on the relationship between tourism sector, trade and growth, and Orieqat and Saymeh (2015) on the effects on job creation, earnings, infrastructure and increase in GDP. While the cited studies showed strong relationship, the results of the current study suggest a moderate relationship.

\section{Conclusion}

This study determined the contribution of the leisure industry and its implemented measures on safety and security toward the economic growth of municipalities in the Laguna Province. It specifically measured the contribution of leisure industry to the overall development of municipalities, assessed the status of implemented measures on safety and security of the leisure industry and described the level of economic growth of municipalities on employment, service and income. This descriptive research employed self-administered questionnaire in four parts to gather data from 100 key stakeholders of leisure industry businesses in the 6 municipalities in district III of Laguna Province. The data were analyzed through average mean, standard deviation and t-test.

The results of the study showed that the leisure industry contributes to the overall development of Municipalities as reflected by the agreement of the respondents on the various indicators assessed. Furthermore, it also disclosed that the status of implemented 
measures on safety and security of the leisure industry in the municipalities had been significant to the growth and development of the industry. Moreover, the level of economic growth in municipalities with regard to employment, service and income was also positively assessed as the key stakeholders agreed on the various indicators. The respondents identified that the leisure industries contribute in the protection of the environment, encourages tourism and promotes awareness of culture and history, and provides a wide range of activities for customers in a safe, secure and responsible environment.

The study provided a background data on the ability of the leisure industry in boosting the municipality income. As it was clearly assessed that the leisure industry generates more income than other industries, it recognizes its capability as a major source of income for the municipalities. It is essential because it can help the municipalities provide more funds for government projects, increase the income and job opportunities for its residents and provide sufficient supply of quality products and services. It should be prioritized to maintain quality, sanitation and safety of the products and services.

The study can help business operators to evaluate their own facilities, products, services, and activities so that they can improve their businesses. This will consequently lead to their increased contribution to their respective community and barangays. As the current study generated data from survey, the results are mere perceptions of the key stakeholders. Further studies are encouraged on the measurement of the actual income contribution of the industry to the municipalities.

\section{References}

Agbor, J.M. (2011) The Relationship between Customer Satisfaction and Service. Umeå School of Business

Anser, M.K., Adeleye, B.N., Tabash, M.I., Tiwari, A.K. (2021) Services trade-ICT-tourism nexus in selected Asian countries:new evidence from panel data techniques. Current Issues in Tourism ), pages 1-16.

Azmat, G., Clemes M. (2021) Business Environment Effect on Business Visitor arrival to New to New Zealand. Current Issues in Tourism 24:17, pages 2445-2457

Bak, S., Min. C. \& Roh, T. (2019) Impact of UNESCO-listed tangible and intangible Heritages on tourism. Journal of Travel \& Tourism Marketing 36:8, pages 917-927

Ballada,W. (2014). Basic Accounting. DomDane Publishers.

Banhidi, M. \& Flack, T. (2013). Changes In Leisure Industry In Europe. International Leisure Review 2 (2), 157-176, 2013. 1, 2013. 
Bascom, C.R. (2016). From Economic Growth to Sustainable Development. The Sustainability Magazine.

Bopp, M., \& Kaczynski, A. T. (2010). Leisure and becoming physically active. In L. Payne, G. Godbey, \& B. Ainsworth (eds.), Leisure, health and wellness: Making the connection, pp. 133-146. State College, PA: Venture Publishing, Inc.

Chung-ki Min, Taek-seon Roh \& Sangmee Bak (2016) Growth effects of leisure tourism and the level of economic development, Applied Economics, 48:1, 7-17, DOI: $10.1080 / 00036846.2015 .1073838$

Dayananda.K.C, \& D.S.Leelavathi. (2016). Tourism Development and Economic Growth in India. Journal Of Humanities And Social Science, 21(11). doi:10.9790/08372111084349

Edginton, C.R. \& Chen, P. (2014). Leisure as Transformation, $2^{\text {nd }}$ Edition. Sagamore Publishing LLC

Hesmondhalgh, D. (2007) The Cultural Industries. Second Edition. London: Sage

Howkins, J. (2001) The Creative Economy: How People Make Money from Ideas. London: Allen Lane.

Kelly, K. (1998). New Rules for the New Economy: 10 Radical Strategies for a Connected World. Fourth Estate, London.

Khalil, S., Kakar, M.K. (2007), Role of tourism in economic growth: Empirical evidence from Pakistan economy. The Pakistan Development Review, 46(4), 985-995.

Kim, H.J., Chen, M., Jan, S. (2006), Tourism expansion and economic development: The case of Taiwan. Tourism Management, 27(5), 925-933.

Lau, G.T. \& Chin, H. W. (2003). Trustworthiness of Salespeople in the Business-to-Business Market: The Five C's. Journal of Business-to-Business Marketing 10, 1-33.

Lee, C., Chang, C.P. (2008), Tourism development and economic growth: A closer look at panels. Tourism Management, 29, 180-192.

Leitner, M.J. \& Leitner, S.F. (2012). Leisure Enhancement. Sagamore Publishing LLC

Mandeep, K. \& Nitasha, S. (2012). Growth and Development of Indian Tourism Industry. Journal of Hospitality Application and Research, Volume 7 Issue 2

Mankiw, N.G. (2011). Principles of Macroeconomics 4th Edition, Thomson SouthWestern

Mikalauskas, R. \& Kaspariene, J. (2016). Holistic approach about leisure industry. Transformations in Business and Economics 15(2):723-740

Mill, R.C.(2017). Introduction To Restaurant Management: Customers Operation and Employment

Minwie, D. (2015). Leisure Sport Industry and Economic Development. Paper presented in the 3rd International Conference on Education, Management, Arts, Economics and Social Science (ICEMAESS 2015)

Norjanah M.B., , Mastura Jaafar \& Diana Mohamad (2014) Perceptions of Local Communities on the Economic Impacts of Tourism Development in Langkawi, Malaysia. SHS Web of Conferences 12, 011

Novak, P. (2017). What Are The 4 Segments Of The Hospitality Industry. HospitalityNet. Available online at: https://www.hospitalitynet.org/opinion/4082318.html

Orieqat, H., Saymeh, A.A.F. (2015), Is tourism a gene sector to Jordan's GDP? International Journal of Development and Economic Sustainability, 3(5), 75-84. 
Ozturk, I., Acaravci, A. (2009), On the causality between tourism growth and economic growth: Empirical evidence from Turkey. The Transylvanian Review of Administrative Sciences, 25E, 73-81.

Romer, P.M. (1990a), "Endogenous technological change", Journal of Political Economy, Vol.98, N 5, pt. 2, pp. S71-S101.

Salleh, N. H. M., Othman, R., Sarmidi, T. (2011), An analysis of the relationships between tourism development and foreign direct investment: An empirical study in selected major asian countries, Int. Journal of Business and Social Science, 2, 250-257.

Sherman, F. (2019). Why Is the Location of a Business Important? Small Business. Chron Magazine.

Ukabuilu, E.N and Igbojekwe P.A (2015) Application of Tourism Economic Development Theories to the Attainment of Goals in Developing Tourism Sites in Cross River State Nigeria. Journal of Tourism, Hospitality and Sports. Vol.13, 2015

World travel and tourism council. (2019). Travel \& Tourism Economic Impact. Retrieved from http://www2.unwto.org/annual-reports 